\title{
Which Needle Needs to Be Chosen for Better Outcome of Endoscopic Ultrasound-Guided Tissue Acquisition?
}

\author{
Dong Wook Lee and Eun Young Kim \\ Department of Internal Medicine, Catholic University of Daegu School of Medicine, Daegu, Korea
}

\begin{abstract}
See "Comparison of the Diagnostic Yield of the Standard 22-Gauge Needle and the New 20-Gauge Forward-Bevel Core Biopsy Needle for Endoscopic Ultrasound-Guided Tissue Acquisition from Pancreatic Lesions" by Shinya Fujie, et al. on page 349, Vol. 13, No. 3, 2019
\end{abstract}

Endoscopic ultrasonography (EUS) has been used in clinical medicine for almost 40 years. ${ }^{1}$ During this period, EUS has become an essential tool for gastrointestinal endoscopy. The development of the linear EUS scope enabled not only direct visualization of the lesions along the path of the scope but also EUSguided tissue acquisition (EUS-TA). Nowadays, EUS-TA serves as one of the best diagnostic choices in many diseases involving the gastrointestinal tract and its adjacent structures. EUS-TA is well known for its high accuracy and safety. However, several factors can affect outcomes of EUS-TA. The endosonographer's experience, the size and location of the lesion, the size and type of the needle, the specific techniques of the procedure, the presence of a cytopathologist for rapid on-site examination, and the cytologist's expertise are some of the important factors that can influence procedure outcomes. ${ }^{2,3}$

In EUS-TA, needles are used for EUS-guided fine-needle aspiration (FNA) and EUS-guided fine-needle biopsy (FNB). Cytological samples obtained by EUS-FNA provide relatively high diagnostic accuracy, but cytological evaluation alone without histology sometimes has limitations in confirming diagnoses. A meta-analysis of the diagnostic performance of EUS-FNA for a solid pancreatic mass showed pooled sensitivity of $87 \%$ and pooled specificity of 96\%. ${ }^{4}$ FNB needles are better to obtain tissue cores than FNA needles. ${ }^{5}$ Tissue cores with preserved architecture and immunohistochemical stain are beneficial for the diagnosis of a few specific diseases, such as mesenchymal tumors, well differentiated adenocarcinomas, lymphomas, cancers in chronic pancreatitis, and autoimmune pancreatitis. In addition, with the rise of personalized medicine, it is now necessary to obtain more tissue for next-generation sequencing, molecular analysis, and organoid generation.

Initially, the 19-gauge Tru-Cut biopsy needle was developed to harvest core tissues. However, this needle presented a host of issues, such as elevated procedure costs and complication rates, difficulty in manipulation, and difficulty in using the transduodenal approach. The EchoTip ProCore ${ }^{\circledast}$ (Wilson-Cook Medical, Winston-Salem, NC, USA) FNB needle was introduced to correct and better serve Tru-Cut needle's identified shortfalls. The 19/22/25-gauge ProCore ${ }^{\circledR}$ needle comes with a reverseside-bevelled architecture at its tip that facilitates core tissue sampling. Although a significant number of studies have evaluated the performance of the ProCore ${ }^{\circledR}$ needle, most studies have not been able to prove its superiority with respect to diagnostic accuracy over the EUS-FNA needle. A meta-analysis showed no significant differences in diagnostic adequacy $(75.2 \%$ vs $89.0 \%$ : odds ratio [OR], 0.39; $\mathrm{p}=0.23$ ), diagnostic accuracy (85.8\% vs 86.2\%: OR, 0.88; $p=0.53$ ), or histological core specimen acquisition (77.7\% vs 76.5\%: OR, 0.94; $\mathrm{p}=0.85$ ) between the 19 -gauge ProCore ${ }^{\circledR}$ and EUS-FNA needles. ${ }^{6}$ However, ProCore ${ }^{\circledR}$ needles had a lower mean required number of needle passes for diagnosis than did EUS-FNA needles (standardized mean difference, 1.2; $\mathrm{p}<0.001)^{6}$

Recently, a 20-gauge antegrade-cutting-side-bevelled biopsy needle (ProCore ${ }^{\circledR}$ ) was developed for EUS-TA. In this issue of Gut and Liver, Fujie et al. ${ }^{7}$ reported their research results in a study entitled "Comparison of the diagnostic yield of the standard 22-gauge FNA needle and the new 20-gauge forwardbevel FNB needle for EUS-TA from pancreatic lesions.” This

\footnotetext{
Correspondence to: Eun Young Kim (https://orcid.org/0000-0003-3965-9964)

Department of Internal Medicine, Catholic University of Daegu School of Medicine, 33 Duryugongwon-ro 17-gil, Nam-gu, Daegu 42472, Korea

Tel: +82-53-650-4092, Fax: +82-53-621-4487, E-mail: kimey@cu.ac.kr pISSN 1976-2283 eISSN 2005-1212 https://doi.org/10.5009/gnl19121

(c) This is an Open Access article distributed under the terms of the Creative Commons Attribution Non-Commercial License (http://creativecommons.org/licenses/by-nc/4.0) which permits unrestricted non-commercial use, distribution, and reproduction in any medium, provided the original work is properly cited.
} 
retrospective comparative study showed similar rates of diagnostic accuracy between the 20-gauge FNB and 22-gauge FNA needles. Technical failure occurred in two patients with the 20-gauge FNB needle. Amazingly enough, two passes with the 20-gauge FNB needle yielded a correct diagnosis in 100\% of patients harvesting core tissue in 90\% of patients with just single pass when technically feasible. This study had limitations, because the procedure was performed with each needle at different time periods, and the specific techniques such as the suction power applied to each needle were different. The range of lesion sizes is widely distributed (17 to $137 \mathrm{~mm}$ vs 10 to $65 \mathrm{~mm}$ ), although mean mass size is similar ( $34 \mathrm{~mm}$ vs $35 \mathrm{~mm}$ ) for the 20-gauge FNB and 22-gauge FNA needles, respectively. Moreover, in this study, diagnostic accuracy and success rate of core TA is too high compared to previous studies regarding the performance of the ProCore ${ }^{\circledR}$ needle. One recent retrospective study compared 20-gauge ProCore ${ }^{\circledR}$ needle with a 22-gauge ProCore ${ }^{\circledR}$ needle for diagnostic performance and histologic retrieval rate in EUS sampling of solid pancreatic lesions. It reported that 20 gauge procured more histologic-grade tissues (92.6\% vs $49.5 \%$, $\mathrm{p}<0.0001$ ) with lower number of passes (2.64 vs 3.44, $\mathrm{p}<0.0001$ ) compared to the 22 gauge. ${ }^{8}$ Antegrade-cutting-side-bevelled design may have contributed in getting significantly more tissue microcores.

Many studies have compared the relationship between needle size and effectiveness. When findings from the literature are compiled, conclusions remain contradictory; some findings indicate that significant differences exist, while others show no differences with respect to needle size and effectiveness. Largebore needles have been shown to produce significantly higher cellular yields but are less successful in approaching the pancreatic head due to its rigidity. The 25 -gauge ProCore ${ }^{\circledR}$ needle was better than other needles at targeting the pancreatic head and uncinate lesions through the transduodenal route. ${ }^{9}$

Which needle is the most ideal for EUS-TA? Various needles have their own advantages and disadvantages in certain aspects, such as visibility, ease of puncture, technical success rate, specimen quality, cost effectiveness, and complication rates. Although FNB needles are more expensive, produce bloodier samples, and induce greater tissue trauma, they provide a large amount of sample, facilitating ancillary testing. In the absence of rapid on-site examination by a cytopathologist, the FNB needle is associated with better diagnostic adequacy in solid pancreatic lesions. In comparision, FNA needles are cheaper, less invasive, and have much lower complication rates than FNB needles.

To choose the correct needle, the endosonographer should first consider the characteristics of the lesion, including location and size. Then, he or she should evaluate the probable diagnosis, since the core biopsy would be essential for diagnosis in certain cases. $^{10}$ If core tissue is needed, the use of an FNB needle or a 19-gauge FNA needle should be considered. If the access route is transduodenal, a 25-gauge needle would be the ideal choice Otherwise, either 22 or 25-gauge needles would be acceptable.

\section{CONFLICTS OF INTEREST}

No potential conflict of interest relevant to this article was reported.

\section{REFERENCES}

1. Kim EY. Introduction; value of endoscopic ultrasound-guided fine needle aspiration. Clin Endosc 2012;45:115-116.

2. Eisendrath P, Ibrahim M. How good is fine needle aspiration? What results should you expect? Endosc Ultrasound 2014;3:3-11.

3. Kim TH. How to improve the diagnostic accuracy of EUS-FNA in abdominal and mediastinal lymphadenopathy? Clin Endosc 2019;52:93-94.

4. Puli SR, Bechtold ML, Buxbaum JL, Eloubeidi MA. How good is endoscopic ultrasound-guided fine-needle aspiration in diagnosing the correct etiology for a solid pancreatic mass?: a metaanalysis and systematic review. Pancreas 2013;42:20-26.

5. Kwon CI. Will new instruments for endoscopic ultrasound-guided tissue acquisition make us happy? Clin Endosc 2018;51:510-512.

6. Bang JY, Hawes R, Varadarajulu S. A meta-analysis comparing ProCore and standard fine-needle aspiration needles for endoscopic ultrasound-guided tissue acquisition. Endoscopy 2016;48:339349.

7. Fujie S, Ishiwatari H, Sasaki K, et al. Comparison of the diagnostic yield of the standard 22-gauge needle and the new 20-gauge forward-bevel core biopsy needle for endoscopic ultrasound-guided tissue acquisition from pancreatic lesions. Gut Liver 2019;13:349355.

8. Armellini E, Manfrin E, Trisolini E, et al. Histologic retrieval rate of a newly designed side-bevelled 20G needle for EUS-guided tissue acquisition of solid pancreatic lesions. United European Gastroenterol J 2019;7:96-104.

9. Kedia P, Gaidhane M, Kahaleh M. Technical advances in endoscopic ultrasound (EUS)-guided tissue acquisition for pancreatic cancers: how can we get the best results with EUS-guided fine needle aspiration? Clin Endosc 2013;46:552-562.

10. Kim EY. Fine-needle biopsy: should this be the first choice in endoscopic ultrasound-guided tissue acquisition? Clin Endosc 2014;47:425-428. 